\title{
Is there a modality effect? Evidence for visual recency and suffix effects
}

\author{
MARCO W. BATTACCHI \\ University of Bologna, Bologna, Italy \\ and \\ GIOVANNA M. PELAMATTI and CARLO UMILTÀ \\ University of Padua, Padua, Italy
}

\begin{abstract}
In Experiment 1, four groups of 16 subjects performed ordered recall of six-syllable lists in both suffix and nonsuffix conditions. Sequential presentation of the lists varied for each group. In the auditory presentation, the syllables were delivered from one location only and were read aloud by the subjects. For the visual, spatially nondistributed presentation, the syllables appeared in one location only and were read silently. For visual, spatially distributed presentations, the syllables were spread out either vertically or horizontally and were read silently. Very robust recency and suffix effects were found in the auditory presentation, as well as in visual, spatially distributed presentations. In Experiment 2, 16 subjects performed ordered recall of visually presented lists with the items spread out vertically and conflicting spatial and temporal orders. A reliable recency effect was found for the final block of trials. In Experiment 3, 16 subjects performed ordered recall in the same conditions as in Experiment 2, except that they were instructed to recall the temporal order in which the spatial positions would be filled in. A bow-shaped curve and a strong recency effect were obtained.
\end{abstract}

In the immediate ordered recall of a list of items presented one at a time, recall of the last one or two items is better following auditory presentation than following visual presentation. This larger recency effect for auditory presentation than for visual presentation, known as the modality effect, is reduced or abolished when an extra item, a suffix, follows the end of the list (the suffix effect ). Until relatively recently, these effects were believed to be well explained by Crowder and Morton's (1969) model of sensory memory (precategorical acoustic storage, or PAS). According to the PAS model, auditory information persists longer in an auditory sensory store than does visual information in a visual sensory store. The sensory, or echoic, trace of a heard list would therefore provide an additional source of information for recall of the last item(s). In contrast, the sensory, or iconic, trace of a seen list, being of much shorter duration, cannot provide extra information. When a suffix is added, it interferes with information about the last item(s) within the acoustic storage and thereby subtracts the additional source of information.

In recent years, results that are not consistent with the PAS model have been accumulating. Modality and suffix effects have been found in many conditions in which no auditory information is available. A modality effect is ob-

Research supported in part by a grant from the Ministry of Education. The authors are greatly indebted to Robert G. Crowder for invaluable suggestions and friendly support. Correspondence should be addressed to Marco W. Battachi, Department of Psychology, Viale Berti Pichat, 5, I-40127 Bologna, Italy. tained when the subject watches an experimenter silently articulate the lists (i.e., the subject lip-reads; see Campbell \& Dodd, 1980, 1982; Gathercole, Gardiner, \& Gregg, 1981). The recency effect in lip-read lists is reduced by a lip-read suffix (Campbell, 1987; Gathercole, 1987; Greene \& Crowder, 1984), as well as by an auditory or mouthed suffix (Campbell, 1987; Campbell \& Dodd, 1980, 1982, 1984; Gathercole, 1987). A lip-read suffix reduces auditory recency (Spoehr \& Corin, 1978). Modality and suffix effects are found in lists of American Sign Language (ASL) signs (Shand \& Klima, 1981) and handsigns (Campbell, Dodd, \& Brasher, 1983).

A modality effect is also obtained in lists that are mouthed or whispered (i.e., articulated silently) by the subject (Crowder, 1986), and this enhanced recency effect is reduced by a mouthed suffix (Greene \& Crowder, 1984; Nairne \& Crowder, 1982; Nairne \& Walters, 1983; Turner et al., 1987), as well as by an auditory suffix (Greene \& Crowder, 1984). Auditory recency is reduced by a mouthed suffix (Greene \& Crowder, 1984; Nairne \& Crowder, 1982).

To sum up, modality and suffix effects are found even when stimuli are presented in the visual modality (lip-read speech sounds, ASL signs, and handsigns) and in the kinesthetic modality (mouthed or whispered speech sounds). Up to now, any attempt to find a common basis to these phenomena has failed. For example, the hypothesis that they may arise whenever the stimuli are presented in a changing-state fashion has received rather weak support. Crowder (1986) found no enhancement of the recency effect when the digits to be recalled were gradu- 
ally drawn or spelled out on the screen. Shand and Klima (1981) found modality and suffix effects in lists of static line drawings of ASL signs. Campbell et al. (1983) showed that movement may be a sufficient, but not a necessary, condition to produce enhanced recency. In fact, the modality effect is also found in lists of still pictures of speech sounds. It is even possible that lipreading and mouthing effects may result from processes different from those that make the standard modality effect occur (Greenberg \& Engle, 1983).

The only generalization that can be drawn is that modality and suffix effects are obtained whenever the lists to be recalled consist of speech-related stimuli or, taking into account also Shand and Klima's (1981) findings, stimuli that mapped onto a primary language code, irrespective of the actual sensory modality in which they were presented (for a general discussion of the recency effects and a framework for their interpretation, see Nairne, 1988).

Regardless of the interpretation offered to explain them, the new findings have compelled a revision of the original PAS model. Crowder's (1983) proposal and those of others (Campbell, 1987; Gathercole, 1987) share the feature of envisaging a storage system specialized for phonetic processing. In this view, modality and suffix effects are conceived to reflect the properties of such a buffer store, which is not purely auditory, nor is it, say, visual or kinesthetic. In fact, it belongs to a more abstract system for phonetic processing.

Even though the new evidence has shaken the theories of echoic memory, the core of the modality-effect phenomenon (i.e., weak recency and suffix effects when verbal items are read silently in a purely visual form) has remained unchallenged and poorly understood (Crowder, 1986). On the basis of evidence for a final-position recency effect in visual memory recognition of hardly nameable stimuli (Christie \& Phillips, 1979; Hines, 1975; Phillips \& Christie, 1977), Broadbent and Broadbent (1981) have even suggested the existence of an undecaying visual sensory memory, quite at variance with the traditional assumption of a fast decay of visual traces (also see Cowan, 1988; and Nairne, 1988; for a similar hypothesis). Thus, in conclusion, there are many reasons to resume the whole problem from its beginning to determine why modality differences in recall are obtained.

Considering the fact that spatial coding is superior in vision and temporal coding is superior in audition (see reviews in Battacchi, 1985; O'Connor \& Hermelin, 1978; and, more particularly for vision and spatial coding, see Keele, Cohen, Ivry, Liotti, \& Yee, 1988; Tsal \& Lavie, 1988), it becomes important to examine the ways in which spatial- and temporal-coding limitations could have invalidated comparisons between the modalities (see Cowan, 1988). It is surprising, therefore, that nobody, with the possible exception of Glenberg and Swanson (1986) and Nairne (1988), has considered the possibility that the modality effect could, in a certain sense, be artifactual. Nairne (1988) suggested that there is more potential for "extraexperimental" stimuli with visual presentation than with auditory presentation, because the end of the list is typically followed by more salient visual events than auditory events. However, the way in which stimuli are distributed in space and time appears to be a better candidate for an explanation.

In the standard experimental conditions, both auditory and visual lists are only temporally distributed (i.e., the items follow one at a time) but come from a unique source or are displayed in just one and the same location. Of course, this is done to allow a comparison between the two modalities. However, one wonders whether this procedure is fair to visual presentation. There is good evidence that processing of temporal and spatial information is modality-specific, in the sense that temporal information is best processed through hearing and spatial information is best processed through vision. For example, the temporal order of a set of stimuli is better remembered when the stimuli are auditory and the spatial order is better remembered when the stimuli are visual (Metcalfe, Glavanov, \& Murdock, 1981; O'Connor \& Hermelin, 1978). A consequence of this modality specificity is that, as was suggested by Glenberg and Swanson (1988), recency differences between modalities may reflect a more fine-tuned encoding of temporal information for auditory presentation than for visual presentation. That is, auditory presentation may lead to a more temporally distinctive memory representation than does visual presentation. It may well be, then, that temporal-order recall of a sequence of visual stimuli that follow one at a time (i.e., are temporally distributed) but are displayed in the same location (i.e., are spatially nondistributed) is less effective than is temporal-order recall of a sequence of auditory stimuli in the same condition of distribution in space and time. Moreover, words typically do not appear one at a time in the same location. Yet, this is exactly what happens with the standard experimental paradigm. Thus, it seems apparent that visual and auditory presentations are not comparable in that paradigm.

A further point worth considering is whether temporalorder recall of a set of visual stimuli is made easier when the stimuli are distributed in such a way that temporal and spatial orders are congruent (e.g., the first in time is also the leftmost in space, and so on; see Anderson, 1976) or are combined into particular temporal-spatial patterns (Healy, 1978). Temporal information could be transferred directly to a more effective spatial code, and recall would be facilitated. In this regard, Giovanelli and Tampieri (1974) found, in children from 4 months of age and older, that it was easier to learn which stimulus would be rewarded in a list of successively presented visual stimuli when the stimuli were spatially distributed than it was when they appeared in only one location.

All considered, it is not unlikely that the auditory-visual modality effect is but a particular instance of a modalityspecific mode of processing temporal and spatial information. Recency and suffix effects would not occur in vision, because the standard experimental situation provides 
only temporal cues for ordered recall. Consequently, one can predict that, if visually presented and silently read items are spread out in space, both recency and suffix effects in temporal-order recall should emerge. Experiment 1 was aimed at testing this prediction.

\section{EXPERIMENT 1}

In Experiment 1, the between-subjects conditions consisted of four kinds of lists that were presented to the subjects: (1) standard auditory presentation, made up of auditory lists: (2) standard visual presentation, consisting of visual lists of items shown in one location only; (3) horizontal visual presentation, visual lists of items spread out horizontally; and (4) vertical visual presentation, visual lists of items spread out vertically. The withinsubjects conditions were (1) whether or not the lists were followed by a suffix, and (2) the serial position of the items within each list.

The hypothesis that the modality effect depends on a modality-specific processing of temporal and spatial information would be supported if comparable recency and suffix effects were obtained with the auditory lists and with the spatially distributed visual lists, but not with the spatially nondistributed visual lists.

\section{Method}

Materials and Design. Lists of six items were constructed from a set of three two-letter syllables that differed in the vowel: pe, $p i, p u$. In every list, each syllable occurred twice in quasirandom strings, with the only constraint being that one syllable could immediately follow the same syllable no more than once in each list. The syllables, printed in capital letters, appeared one at a time on the terminal screen of an Apple IIE computer. Their size was $5 \mathrm{~mm}$ in height and $4 \mathrm{~mm}$ in width. In the visual conditions, the subjects were instructed to read the syllables silently; in the auditory condition, they were instructed to read the syllables aloud. Note that it makes no difference whether the source of the auditory stimulation is the subject's own voice or that of an external speaker (Greene \& Crowder, 1984). Each syllable of every list appeared exactly on the center of the screen in the conditions of standard auditory presentation and standard visual presentation (items centered in the same location). In the horizontal and the vertical visual presentations, the syllables of every list were centered vertically and spread out horizontally or centered horizontally and spread out vertically, respectively. The distance between each of the two locations was $2 \mathrm{~cm}$. The approximate viewing distance was $50 \mathrm{~cm}$.

Procedure. The subjects were told that they were in an experiment on short-term memory. Each trial began $0.5 \mathrm{sec}$ after a 1000 $\mathrm{Hz}$ tone was presented. Then, the six syllables of a list appeared, one at at time, at every half second. Each syllable was presented for $200 \mathrm{msec}$. In both the standard auditory presentation and the standard visual presentation, after the six syllables had been shown, either the syllable PA (the suffix condition) or a square approximately the same size as a written syllable (the nonsuffix condition) appeared in the center of the screen. In the horizontal and the vertical visual presentations, the extra syllable or the square appeared either to the right of or below the final list item. Only in the auditory presentation was the suffix syllable to be read aloud. Immediately after the suffix syllable or the square had appeared, the subjects were to write down on an appropriate sheet of paper the syllables they had seen on the basis of the temporal order of presentation. The interlist interval was $10 \mathrm{sec}$.
Each group of subjects participated in only one presentation condition, but in both the suffix and the nonsuffix condition. Half of each group started with the suffix condition and the other half with the nonsuffix condition. Fifteen trials were performed for each condition. Practice trials in which different lists were visually presented in the same location ensured that the subjects understood the instructions

The experimenter warned the subjects in the silent reading condition to avoid mouthing or whispering the stimuli and sat about $1.5 \mathrm{~m}$ in front of them to ensure compliance with the instructions.

Subjects. Sixty-four students of the University of Padua (32 males and 32 females) participated in Experiment 1 . They were randomly assigned such that there were 16 subjects ( 8 males and 8 females) in each of the four stimulus-presentation conditions.

\section{Results}

The results are shown in Figure 1. It is immediately apparent that, besides the usual modality effect in the standard auditory and visual presentations, there are dramatic recency and suffix effects when the visual stimuli are spread out in space.

The results are presented in detail according to analyses of variance (ANOVAs), with .05 rejection regions, performed only on Positions 5 and $6 .{ }^{1}$ A separate ANOVA for repeated measures was performed for each of the four presentation conditions. Every ANOVA had two main factors: suffix condition (suffix vs. nonsuffix) and serial position (Position 5 vs. Position 6). Note that the serialposition factor measured the recency effect.

In the auditory presentation, percentages of errors on Positions 5 and 6 were 71.2 and 35.4, respectively, for the nonsuffix condition, and 67.5 and 61.6 , respectively, for the suffix condition. The two main effects and the interaction were significant [for the suffix effect, $F(1,15)=$ $11.596, M S_{\mathrm{e}}=45.56, p=.004$; for serial position, $F(1,15)=176.887, M S_{\mathrm{e}}=156.25, p<.001$; and for the interaction, $F(1,15)=105.652, M S_{\mathrm{e}}=81.0, p<$ $.001]$.

In the standard visual presentation, percentages of errors on Positions 5 and 6 were 86.6 and 84.2, respectively, for the nonsuffix condition, and 88.3 and 82.1 , respectively, for the suffix condition. A small recency effect was not affected by the suffix; only the factor of serial position was significant $\left[F(1,15)=7.737, M S_{\varepsilon}=6.89\right.$, $p<.02]$.

In the visual presentation with stimuli spread out horizontally, percentages of errors on Positions 5 and 6 were 75.0 and 49.2 , respectively, for the nonsuffix condition, and 67.9 and 62.5 , respectively, for the suffix condition. The recency effect and a selective suffix effect were both significant [for serial position, $F(1,15)=130.371$, $M S_{\mathrm{e}}=95.06, p<.001$; for the interaction, $F(1,15)=$ $\left.19.887, M S_{\mathrm{e}}=33.06, p<.001\right]$.

In the visual presentation with stimuli spread out vertically, percentages of errors on Positions 5 and 6 were 73.3 and 39.2 , respectively, for the nonsuffix condition, and 68.7 and 59.6 , respectively, for the suffix condition. The recency effect, the suffix effect, and the interaction were all significant [for the suffix condition, $F(1,15)=5.212$, $M S_{\mathrm{e}}=22.56, p<.04 ;$ for serial position, $F(1,15)=$ 


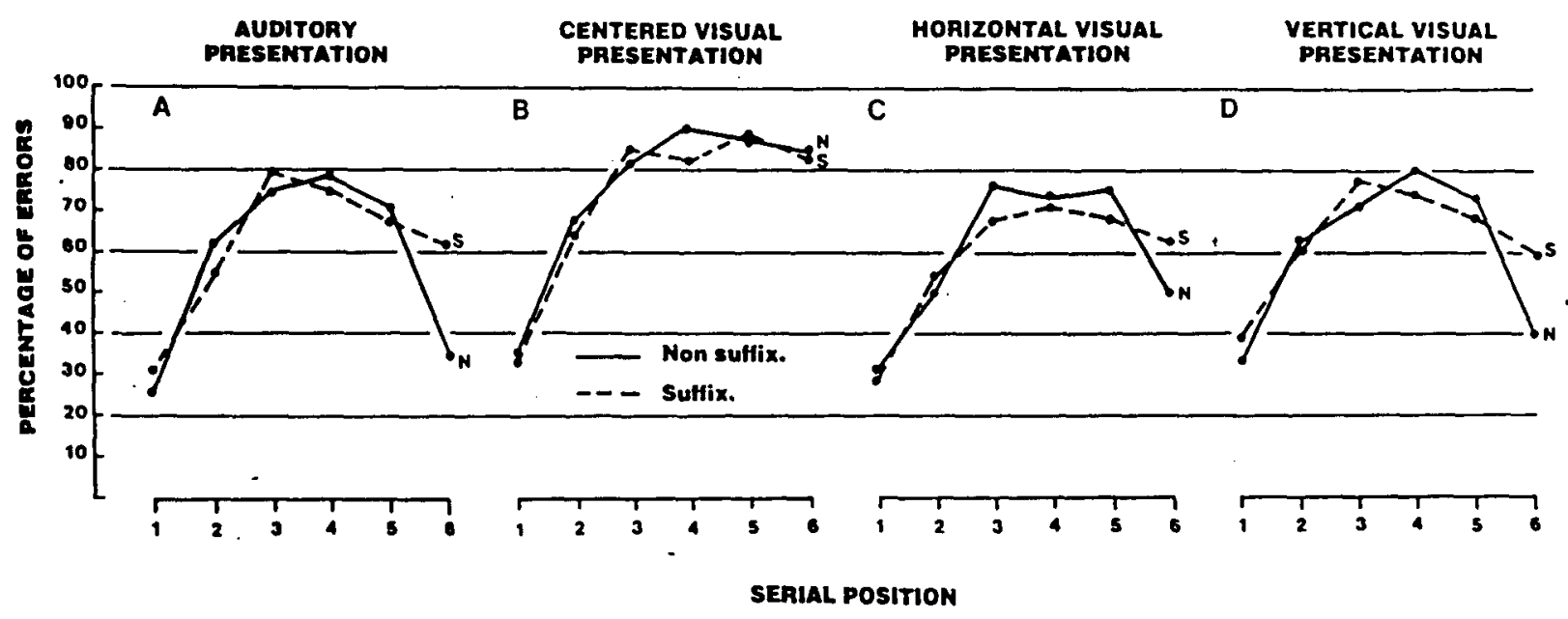

Figure 1. Mean percentage of errors as a function of suffix condition (suffix/nonsuffix) $\times$ serial position (1-6).

99.412, $M S_{\mathrm{e}}=169.0, p<.001$; for their interaction, $\left.F(1,15)=36.290, M S_{\mathrm{e}}=56.25, p<.001\right]$.

Apparently, recency and suffix effects are obtained when visual stimuli are spread out in space, regardless of whether the axis along which they are distributed is horizontal or vertical. An ANOVA for mixed design, taking into account the spatial axis as the between-subjects factor and suffix condition and serial position as the within-subjects factors, showed that there was no significant difference due to the way stimuli were displaced in space [for spatial axis, $F(1,30)=1.535, M S_{\mathrm{e}}=7.03$, n.s.; for the suffix condition, $F(1,30)=4.662, M S_{\mathrm{e}}=$ $19.53, p<.04$; for serial position, $F(1,30)=213.062$, $M S_{\mathrm{e}}=258.78, p<.001$; for the interaction between suffix condition and serial position, $F(1,30)=54.649$, $\left.M S_{\mathrm{e}}=87.78, p<.001\right]$.

These rather unusual findings deserved a closer analysis. Thus, the data in the visual, spatially nondistributed presentation were compared with the data in the two visual spatially distributed presentations, which were pooled together. As far as Positions 5 and 6 are concerned, the difference between the nondistributed presentation on one side and the distributed ones on the other was highly significant [for spatial distribution, $F(1,30)=117.401$, $M S_{\mathrm{e}}=400.80, p<.001$; for the interaction of spatial distribution with serial position, $F(1,30)=57.469$, $M S_{\mathrm{e}}=37.73, p<.001$; for the interaction of spatial distribution with suffix condition and serial position, $\left.F(1,30)=36.513, M S_{\mathrm{e}}=30.52, p<.001\right]$.

Finally, a comparison was made between the auditory presentation and the spatially distributed visual presentations pooled together. The ANOVA showed no significant difference between modalities. Neither the main effect of modality (auditory vs. visual) nor its interactions with suffix condition and serial position (Position 5 vs. Position 6) reached significance. In contrast, suffix condition $\left[F(1,30)=16.026, M S_{\mathrm{e}}=48.14, p<.001\right]$, serial position $\left[F(1,30)=434.80, M S_{e}=283.52, p<\right.$
$.001]$, and the interaction $\left[F(1,30)=144.255, M S_{\mathrm{e}}=\right.$ $123.05, p<.001]$ were significant.

\section{Discussion}

On the basis of the notion that spatial information is more relevant in vision (and temporal information is more relevant in audition), we reasoned that a more appropriate way to test recency and suffix effects in vision would have been through the presentation of stimuli spread out in space. As predicted, recency and suffix effects were found with visually presented lists when the items were spatially distributed. Note that a possible artifactual influence of covert mouthing can be easily ruled out, because there is no reason to think that the effect of mouthing manifests itself only when the stimuli are spatially distributed.

It is worth pointing out that these results are not entirely new. Turner et al. (1987) obtained some evidence of this kind, but they apparently did not pay too much attention to it, perhaps because their data were not as clearcut as ours. In their Experiment 2, lists of words were visually presented by spreading out the words vertically. Inspection of their graphs shows a small recency effect and a more marked suffix effect. Broadbent and Broadbent (1981), in their experiments of visual memory recognition, found a dramatic change in performance, depending on whether the items were presented in the same location or were successively displayed along the horizontal axis. In contrast, Frick (1985) found no improvement in recall with sequential presentation of visual stimuli (digits) when they were distributed in space. However, there is good evidence that, in Frick's study, sequential presentation did not elicit use of visual memory (see discussion of Experiment 2).

If we accept the combination of recency and suffix effects as sufficient criterion for sensory memory, it appears that, in accordance with what was suggested by Cowan (1988), visual memory traces decay slowly enough to al- 
low a recency effect to occur, provided that visual stimuli are distributed in space. However, the contention that visual recency and suffix effects originate from a modality-independent memory store (whereas auditory recency depends on the properties of an auditory sensory store) cannot be ruled out so easily, because there is some evidence (Hitch, 1975; Kahneman, 1973) that the visual suffix effect may result from a failure to exclude the suffix from attentive processing (attentional hypothesis).

Hitch (1975) showed that, with practice, it becomes easier to ignore the suffix because the subject learns to exclude it from focal attention. Therefore, one would think that the failure in attentional control is more likely to occur at the beginning than at the end of the subjects' performance. Consequently, the suffix effect should decrease (conversely, the recency effect should increase) from the first to the final trials. To test this prediction, the data were submitted to a further analysis by partitioning the whole set of trials into three blocks of five trials: the initial (Trials 1-5), the central (Trials 6-10), and the final (Trials 11-15). If the recency effect is larger for the last block(s), there is evidence in support of the attentional hypothesis; however, if there is no difference in recency across blocks, the attentional hypothesis is not supported.

A two-way ANOVA for repeated measures was performed, with serial position (Positions 5 and 6) and block order (initial, central, and final) as the main factors. In both the vertical and the horizontal visual presentations, neither block order nor the interaction of block order with serial position was significant for the suffix condition. [Vertical presentation: for block order, $F(2,15)=0.958$, $M S_{\mathrm{e}}=0.760$; for the interaction, $F(2,30)=2.754, M S_{\mathrm{e}}$ $=1.448$. Horizontal presentation: for block order, $F(2,15)=1.675, M S_{\mathrm{e}}=1.323$; for the interaction, $F(2,30)=0.138, M S_{\mathrm{e}}=0.135$.]

It is worth noting that the same result was obtained for the nonsuffix conditions in both vertical and horizontal visual presentations. [Vertical presentation: for block order, $F(2,15)=2.063, M S_{e}=1.531$; for the interaction, $F(2,30)=0.091, M S_{\mathrm{e}}=0.073$. Horizontal presentation: for block order, $F(2,15)=1.810, M S_{e}=1.167$; for the interaction, $F(2,30)=0.071, M S_{e}=0.042$.]

Furthermore, the same result was obtained for both the suffix and nonsuffix conditions in the standard visual presentation. [Suffix condition: for block order, $F(2,15)=$ $1.723, M S_{\mathrm{e}}=0.635$; for the interaction, $F(2,30)=$ 2.987, $M S_{\mathrm{e}}=0.969$. Nonsuffix condition: for block order, $F(2,15)=1.376, M S_{\mathrm{e}}=0.406$; for the interaction, $F(2,30)=0.379, M S_{\mathrm{e}}=0.135$.]

In brief, no change in recall performance was ever found to occur across trials. Admittedly, this is not a strong test of the attentional hypothesis because it rests on a lack of evidence in favor of it, and not on evidence against it. For example, one might contend that merely going on with the trials does not allow the subjects to gain enough attentional control. However, this evidence is not as weak as it seems to be. In fact, in Experiment 2, the attentional hypothesis, which was well founded in that case, received strong support by an analysis by blocks.
At any rate, even if visual recency and suffix effects were due to modality-independent memory processing, the reason why the visual-auditory modality effect is found only in the standard experimental conditions (and not in the conditions of spatial distribution of the visual stimuli) is yet to be explained.

The results of the present experiment lead to the conclusion that any model that attempts to accommodate all the findings about the modality effect must take into consideration the modality-specific processing of time and space. The following tentative proposal is just a first step in that direction.

Recency effects are assumed to be due to the fact that memory traces for the final item(s) in a list tend to possess more identifying features, because less, or no, overwriting or interference occurs from subsequent input. The surviving trace features will aid recall as long as they provide discriminative information about an item. It follows that, if the items in the set are poorly discriminable, very little discriminative information can be provided by the surviving traces, and, because of this, recency will be absent or sharply reduced (Nairne, 1988). This is exactly what has been found when auditory lists of high interitem similarity are used (Battacchi, Pelamatti, \& Umiltà, 1989; Crowder, 1971; Darwin \& Baddeley, 1974; Watkins, Watkins, \& Crowder, 1984), and there is no reason to limit the effect of stimulus similarity to audition. (It should be noted that this account may hold for modality-dependent, as well as modality-independent, memory traces.)

Now, assuming that visual input induces the selection of spatial dimensions for coding and that auditory input induces the selection of temporal dimensions, it is likely that each visually presented item is marked by its spatial location, ${ }^{2}$ whereas each auditorily presented item is marked by its relative temporal position. As a consequence, if the visual items in a list appear in the same location, they receive the same spatial mark and are rendered more similar than they would be if each had received a different spatial mark (Broadbent \& Broadbent, 1981).

If modality-dependent traces are available, a sort of spatial iconic masking or visual interference (Parkinson, Kroll, \& Parks, 1973) can even be proposed. Two successive visual stimuli that occupy the same location mask each other in the same way as do two simultaneous auditory stimuli that issue from different sources. Furthermore, consider that, with lists of six items from a vocabulary of size 3 , each item is repeated twice and its position in the list is a necessary feature for identification. In the standard visual presentation, however, the spatial position of all items is exactly the same and the identification function of spatial position is missing. In these conditions, recency and suffix effects are unlikely to be found.

\section{EXPERIMENT 2}

In the conditions of spatial distribution of Experiment 1, each item of a list did not only appear in a different location, but was also ordered spatially in such a way that 
temporal and spatial orders were congruent. Consequently, which factor was responsible for the visual recency and suffix effects is not known. Note that spatialorder information may contribute to retention of temporalorder information, if the two orders are congruent, and thus prevent the loss of order information, which, in Experiment 1 , was an identifying feature of list items.

Another experiment was conducted, in which spatial and temporal orders did not coincide. If recency effect is obtained also in this condition (only recency was tested in this case), spatial distribution per se, and not spatialtemporal congruency, is the relevant factor and the spatialmark hypothesis is supported. If the recency effect is absent or sharply reduced, the relevance of spatial-temporal congruency is strongly supported.

\section{Method}

Materials, Design, and Procedure. The same materials and procedure used in Experiment 1 were again used in Experiment 2. Only the nonsuffix condition of silent visual presentation with the items spread out vertically was tested. Temporal and spatial order never coincided. In other words, Item $\mathrm{N}$ temporally never occurred in Position $\mathbf{N}$ spatially. Each subject performed 15 trials.

Subjects. Sixteen students of the University of Padua $(8$ males and 8 females) participated in Experiment 2.

\section{Results}

The results are shown in Figure 2. It is apparent that a strong recency effect was obtained even in the presence of spatial-temporal conflict. Percentages of errors on Positions 5 and 6 were 75.0 and 67.5 , respectively. A oneway ANOVA performed on Positions 5 and 6 showed that the difference is significant $\left[F(1,15)=13.966, M S_{\mathrm{e}}=\right.$
$10.125, p=.002]$. However, these results cannot be accepted as reliable evidence for a recency effect because the number of errors was well above chance level at every serial position. Apparently, spatial-order information was processed even if it was not task-relevant and interfered with retention of temporal order. In other words, temporal-order recall was impeded because there was a strong tendency to recall the items in their spatial, rather than temporal, order. Remember that the two orders never coincided.

It is a reasonable hypothesis that the interference of spatial order may be the result of a failure in attentional control. If so, the interference is likely to decrease from the initial to the final trials.

The data were submitted to further analysis by partitioning the total set of trials into three successive blocks of five trials; a two-way ANOVA for repeated measures was performed. Serial position (Positions 5 and 6) and block order (initial, central, and final) were the main factors. Both serial position and block order were significant [for serial position, $F(1,15)=15.068, M S_{\mathrm{e}}=4.594$, $p=.001$; for block order, $F(2,15)=19.994, M S_{\mathrm{e}}=$ $10.760, p<.001]$, whereas their interaction was not $\left[F(2,30)=1.948, M S_{e}=0.594, p=.158\right]$. Separate one-way ANOVAs were then performed on Positions 5 and 6 for each block. For the initial block, percentages of errors were 86.2 and 81.2 , respectively (i.e., well above chance level), and the difference was not significant $\left[F(1,15)=3.151, M S_{\mathrm{e}}=0.781, p>.05\right]$. For the central block, percentages of errors were 72.5 and 67.5 , respectively, and again the difference was not significant $\left[F(1,15)=2.143, M S_{e}=0.500, p=.161\right]$. For the fi-

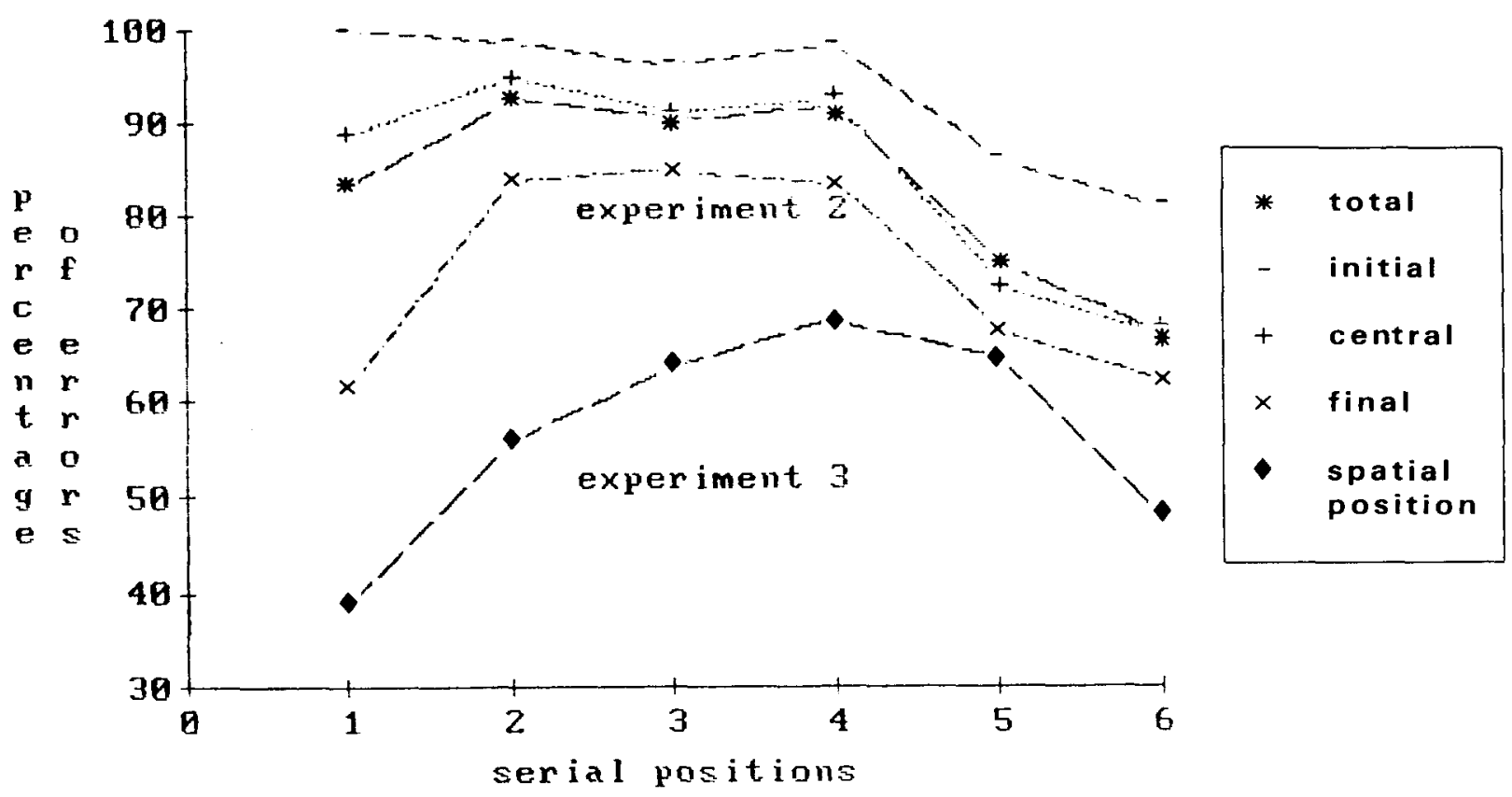

Figure 2. Mean percentage errors as a function of conflicting spatial and temporal orders. Experiment 2: Data of total set of lists and data partitioned into successive blocks of trials. Experiment 3: Recall of spatial positions. Item information to be disregarded. 
nal block, percentages of errors were 67.5 and 52.5 , respectively, and the difference was significant $[F(1,15)=$ 10.38, $\left.M S_{\mathrm{e}}=4.50, p=.005\right]$.

\section{Discussion}

It is apparent that, when the subjects succeeded in disregarding spatial order, a reliable recency effect was obtained. This recency effect can be due only to spatial distribution per se.

Processing of irrelevant and conflicting spatial order interfered with retention of temporal order. It is a plausible assumption that, in order to reduce spatial-temporal conflict, the items were recalled in accordance with their position in the dominant spatial code. The dominance of the task-irrelevant spatial code supports the conclusion that a visual store is involved even in sequential (and not only in simultaneous) presentation, provided that the items are distributed in space.

\section{EXPERIMENT 3}

The very high level of errors found in Experiment 2, where spatial and temporal orders conflicted, can be explained by assuming that, in visual presentation, the item position in the spatial code was dominant. Temporally ordered recall in conditions of spatial-temporal conflict is no doubt an exacting task. It implies processing item information, temporal-order information, and, though irrelevant, spatial-order information. Therefore, error rate is likely to decrease if one type of information is excluded from the task demands.

Experiment 3 was performed, requiring the subject to recall the temporal order in which the spatial positions would be filled in, regardless of the item shown in each position. In other words, only spatial and temporal information, and not item information, was task-relevant.

\section{Method}

Materials, Design, and Procedure. With the exception of the instructions, the materials, design, and procedure used in Experiment 3 were the same as those used in Experiment 2. The subjects were provided with the six spatial positions arranged vertically as on the screen and were instructed to mark down each spatial position using digits 1-6, in accordance with the temporal order in which each spatial position was filled in by an item.

Subjects. Sixteen students of the University of Padua ( 8 males and 8 females) participated in Experiment 3.

\section{Results}

As shown in Figure 2, a beautiful bow-shaped curve was obtained and errors were well below chance level. In particular, a very robust recency effect was found. Percentages of errors in Positions 5 and 6 were 64.4 and 47.9, respectively, and the difference was significant $[F(1,15)$ $\left.=150.0, M S_{\mathrm{e}}=50.0, p<.001\right]$.

\section{Discussion}

First of all, it must be noted that a classic bow-shaped curve and a strong recency effect were found in a situation in which temporal and spatial orders were conflict- ing. Second, it is almost impossible to avoid the conclusion that in retaining the temporal order in which spatial positions were filled in, a purely visual store was at work. In fact, it is very unlikely that the subjects encoded the labels for spatial positions in a speech-like form (the inner voice), because the digits 1-6 were used as labels to encode temporal order. Furthermore, it is also very unlikely that the subjects retained temporal order only by encoding the labels for temporal positions in a speechlike form. It is exactly this processing of modalityindependent features that, without the support of residual auditory traces, predicts the absence of a recency effect (Nairne, 1988). Third, a strong recency effect was obtained when item information could be disregarded. It is likely that visual sequential presentation, even though spatially distributed, may not elicit use of visual memory, as in Frick's (1985) experiments, if item information must be retained. In this case, subjects tend to rely on speechbased recoding of visual stimulus items, and the contribution of visual memory may be entirely lost.

\section{CONCLUSIONS}

In Experiment 1, the subjects performed ordered recall of six-syllable lists in both suffix and nonsuffix conditions. Presentation of the lists was different. In the auditory presentation, the syllables were delivered from one location only and were read aloud by the subjects. For visual, spatially nondistributed presentation, the syllables appeared in one location only and were read silently. For visual, spatially distributed presentations, the syllables were spread out either vertically or horizontally and were read silently. Very robust recency and suffix effects were found in auditory presentation, as well as in the visual, spatially distributed presentations. These findings, which challenge the classic, auditory-visual modality effect, suggest that any general model of the modality effect must take into consideration the modality-specific processing of time and space.

In Experiment 2, the subjects performed ordered recall of visually presented lists with the items spread out vertically and conflicting spatial and temporal orders. A reliable recency effect was found for the final block of trials. This finding shows that the visual recency effect is due to spatial distribution per se.

In Experiment 3, the subjects performed ordered recall in the same conditions as in Experiment 2, except that they were instructed to recall the temporal order in which the spatial positions would be filled. A beautiful bowshaped curve and a strong recency effect were obtained. The findings support the conclusion that a purely visual store was at work and that the contribution of visual memory may be lost when item information must also be retained.

\section{REFERENCES}

Anderson, R. E. (1976). Short-term retention of the where and when of pictures and words. Journal of Experimental Psychology: General, $105,378-402$ 
Battacchi, M. W. (1985). Research on the chronotope. Teorie $e$ Modelli, 2, 135-152.

Battacchi, M. W., Pelamatti, G. M., \& Umiltà, C. (1989). Multiple mechanisms for recency with vowels and consonants. Memory \& Cognition, 17, 329-336.

Broadbent, D. E., \& Broadbent, M. H. P. (1981). Recency effects in visual memory. Quarterly Journal of Experimental Psychology, 33A, $1-15$.

Camprell, R. (1987). Common processes in immediate memory: Precategorical acoustic storage and some of its problems. In A. Allport, D. G. Mackay, W. Prinz, \& E. Scheerer (Eds.), Language perception and production (pp. 131-150). London: Academic Press.

Camprell, R., \& Dodd, B. (1980). Hearing by eye. Quarterly Journal of Experimental Psychology, 32, 85-99.

Camprell, R., \& Dodd, B. (1982). Some suffix effects on lipread lists. Canadian Journal of Psychology, 36, 509-515.

Campeell, R., \& Dodd, B. (1984). Aspects of hearing by eye. In H. Bounma \& D. Bouwhuis (Eds.), Attention and Performance (Vol. 10, pp. 299-312). Hillsdale, NJ: Erlbaum.

CAmpbell, R., DodD, B., \& Brasher, J. (1983). The sources of visual recency: Movement and language in serial recall. Quarterly Joumal of Experimental Psychology, 35A, 571-587.

Christie, D. F. M., \& Phillips, W. A. (1979). Simple drawing and pattern completion techniques for studying visualization and long-term visual knowledge. Memory \& Cognition, 7, 360-367.

Cowan, N. (1988). Evolving conceptions of memory storage, selective attention, and their mutual constraints within the human information-processing system. Psychological Bulletin, 104, 163-191.

CrowDER, R. G. (1971). The sounds of vowels and consonants in immediate memory. Cognitive Psychology, 1, 157-178.

Crowder, R. G. (1983). The purity of auditory memory. Philosophical Transactions of the Royal Society of London, B, 302, 241-265.

CrowDER, R. G. (1986). Auditory and temporal factors in the modality effect. Journal of Experimental Psychology: Learning; Memory, \& Cognition, 12, 268-278.

Crowder, R. G., \& Morton, J. (1969). Precategorical acoustic storage (PAS). Perception \& Psychophysics, 5, 365-373.

DARWIN, C. J., \& BADDELEY, A. D. (1974). Acoustic memory and the perception of speech. Cognitive Psychology, 6, 41-60.

FrICK, R. A. (1985). Testing visual short-term memory: Simultaneous versus sequential presentations. Memory \& Cognition, 13, 346-356.

GATHERCOLE, S. E. (1987). Lip-reading: Implications for theories of short-term memory. In D. Dodd \& R. Campbell (Eds.), Hearing by eye (pp. 227-241). Hillsdale, NJ: Erlbaum.

Gathercole, S. E., Gardiner, J., \& GreGG, V. (1981). Effects of auditory and lipspoken distraction on the modality effect in recall. Paper presented at the meeting of the Experimental Psychology Society, Oxford.

Giovanelli, G., \& Tampieri, P. (1974). Osservazioni sui processi di interazione spazio-temporale nella prima infanzia. Aggiornamenti dell'Istituto di Psicologia dell'Università di Bologna.

GlenberG, A. M., \& Swanson, G. (1986). A temporal distinctiveness theory of recency and modality effect. Joumal of Experimental Psychology: Learning, Memory, \& Cognition, 12, 3-15.

GreENBERG, S. N, \& ENGLE, R. W. (1983). Voice changes in the stimulus suffix effect: Are the effects structural or strategic? Memory \& Cognition, 11, 551-556.

Greene, R. L., \& Crowder, R. G. (1984). Modality and suffix effects in the absence of auditory stimulation. Journal of Verbal Leaming \& Verbal Behavior, 23, 371-382.
Healy, A. E. (1978). A Markov model for the short-term retention Journal of Experimental Psychology, 90, 128-135.

Hines, D. A. (1975). Immediate and delayed recognition of sequentially presented abstract shapes. Journal of Experimental Psychology: Human Learning \& Memory, 1, 634-635

Hiтch, G. I. (1975). The role of attention in visual and auditory suffix effects. Memory \& Cognition, 3, 501-505.

Kahneman, D. (1973). Attention and effort. Englewood Cliffs, NJ Prentice-Hall.

Keele, S. W., Cohen, A., Ivry, R., Liotti, M., Yee, P. (1988) Tests of a temporal theory of attentional binding. Joumal of Experimental Psychology: Human Perception \& Performance, 14, 444-452.

Metcalfe, J., Glavanov, D., Murdock, M. (1981). Spatial and temporal processing in the auditory and visual modalities. Memory \& Cognition, 9, 351-359.

NAIRNE, J. S. (1988). A framework for interpreting recency effects in immediate serial recall. Memory \& Cognition, 16, 343-352.

Nairne, J. S., \& Crowder, R. G. (1982). On the locus of the stimulus suffix effect. Memory \& Cognition, 10, 350-357.

NaIRNe, J. S., \& Walters, V. L. (1983). Silent mouthing products modality- and suffix-like effects. Journal of Verbal Learning \& Verbal Behavior, 22, 475-483.

NisSEN, M. J. (1985). Accessing features and objects: Is location special? In M. I. Posner \& O. S. M. Marin (Eds.), Attention and performance (Vol. 11, pp. 205-219). Hillsdale, NJ: Erlbaum.

O'Connor, N., \& HERMELIN, B. (1978). Seeing and hearing and space and time, London: Academic Press.

Parkinson, S. R., Kroll, N. E. A., Parks, T. E. (1973). Shortterm retention of superimposed and of spatially distinct multiletter visual arrays. Memory \& Cognition, 1, 301-303.

Phillips, W. A., \& Christie, D. F. M. (1977). Components of visual memory. Quarterly Joumal of Experimental Psychology, 29, 117-133.

SHAND, M. A., KLIMA, E. S. (1981). Nonauditory suffix effects in congenitally deaf signers of American Sign Language. Journal of $E x$ perimental Psychology: Human Learning \& Memory, 7, 464-474.

SPOEHR, K. T., \& Corin, W. J. (1978). The stimulus suffix effect as a memory coding phenomenon. Memory \& Cognition, 6, 583-589.

Tsal, Y., \& LAVIE, N. (1988). Attending to color and shape: The special role of location in selective visual processing. Perception \& Psychophysics, 44, 15-21.

Turner, M. L., La Pointe, L. B., Cantor, J., Reeves, C. H., Griffeth, R. H., \& ENGLE, R. W. (1987). Recency and suffix effects found with auditory presentation and with mouthed visual presentation: They're not the same thing. Journal of Memory \& Language, 26, 138-164.

Watkins, M. J., Watkins, O. C., \& Crowder, R. G. (1974). The modality effect in free and serial recall as a function of phonological similarity. Journal of Verbal Learning \& Verbal Behavior, 13, 340-447.

\section{NOTES}

1. All of the analyses reported in this study were performed on raw data (i.e., error rate). Note, however, that, in both the text and the figures, results are presented as percentages of errors.

2. For similar proposals see, for example, Keele et al. (1988), Nissen (1985), and Tsal and Lavie (1988).

(Manuscript received May 26, 1989; revision accepted for publication May 14, 1990.) 